\title{
The International Year of Statistics: A Celebration and A Call to Action
}

Marie DAVIDIAN

Marie Davidian is 2013 President, American Statistical Association, and William Neal Reynolds Professor, Department of Statistics, North Carolina State University, Raleigh, NC 27695-8203 (Email: davidian@ncsu.edu).

\section{INTRODUCTION: A CRITICAL JUNCTURE}

We are almost two-thirds of the way through 2013, the International Year of Statistics. Statistics2013, as it is also known, is a year-long recognition of the impact of our discipline on science and society. Almost daily, events are taking place across the globe highlighting the contributions of statistics to just about everything. Improving human health. Understanding our environment. Informing decision-making in business and in government.

All of us here in this room know the importance of our field. Statistics2013 is devoted to sharing that knowledge - with fellow scientists, industry leaders, government policymakers, students, the media, and the public. Raising awareness of how statistics and statistical thinking affect every one of us will expand opportunities for us to make a difference. And will attract students to the study of statistics, which is essential to meeting the demands posed by this new, data-driven age. And, ultimately, will increase the ability of the public to make sense of what those data mean to them. 
When it came time for me to choose the theme for these Joint Statistical Meetings (JSM), I naturally chose "Celebrating the International Year of Statistics." Because we have much to celebrate! At the same time, our discipline and our profession are at a critical juncture.

On the one hand, statistics and statisticians have been getting a good deal of attention recently. In the media and among students in particular.

On the other hand, our field has been nearly invisible in key arenas, especially in the ongoing discourse on Big Data and data science. At no time have statistical principles and our skills been more relevant or more essential. Which makes the disconnect between our field and this discourse of great concern.

Tonight, I would like to take you on a brief tour of both sides of this story. I hope to convince you of why I say we are at a crossroads that demands that we take action. And I hope to inspire you to join in the efforts of our association, the American Statistical Association (ASA), in confronting this challenge.

I will do this by discussing three things. First, I will present examples of both the positive attention and lack of visibility recently afforded to our discipline. Second, I will describe what the ASA has done and is doing to capitalize on the positive attention and to address the disconnect. And how the International Year is promoting the role of statistics throughout society (and how 2013 became the International Year in the first place). Finally, I will turn to to what we - as individuals, an association, and a profession - can do, in the rest of this year and beyond, to ensure that statistics and statisticians are at the table. Making the contributions for which we are uniquely qualified as the data revolution evolves. 


\section{VISIBILITY, AND LACK THEREOF}

\subsection{Visibility of Statistics}

You may not remember where you were four years ago this week. But chances are you were at the 2009 JSM in Washington, DC, the most highly attended JSM ever, with over 6,800 participants. On the last day of the meeting, an article appeared in the The New York Times entitled, "For Today's Graduate, Just One Word: Statistics" (Lohr, 2009). It spoke of the "rising stature of statisticians" and of the growing interest in the field, inspired by the "data surge." But what really made this article resonate with our community was the now-immortal quote by Hal Varian, chief economist at Google: "I keep saying that the sexy job in the next 10 years will be statisticians. And I'm not kidding." That statement has been repeated in the media and within our profession enough times that, four years later, being "sexy" has become almost tiresome. But it's hard to complain.

Since then, similar media accounts have highlighted our discipline, with titles like "What are the Odds that Stats Would be This Popular?" in 2012 (Hardy, 2012) in the The New York Times and "The Allure of the Statistics Field Grows" in The Boston Globe (Teitell, 2012), for which ASA Past president Bob Rodriguez and I were interviewed at the end of last year.

Carl Bialik, "The Numbers Guy" who writes a column and blog for the The Wall Street Journal, has devoted several of them to statistics. Last December, he discussed the importance of statistics and statistical literacy and gave a plug for the International Year (Bialik, 2012). In March, he focused on the surge of interest in statistics among college students and the continuing growth in participation of high school students in the Advanced Placement Statistics exam (Bialik, 2013). Indeed, 
as Bob noted in one of his Amstat News columns last year (Rodriguez, 2012), the numbers of undergraduates seeking to major in statistics on many campuses have been increasing dramatically.

The single most influential event drawing attention to our field was the 2012 U.S. presidential election. Nate Silver, who spoke to us yesterday, turned the political world on its head with his spot-on, state-by-state predictions of the outcome on his FiveThirtyEight blog. Using statistical modeling! Not only has Nate become a veritable rock star, but he and his best-selling book, The Signal and the Noise: Why So Many Predictions Fail but Some Don't (Silver, 2012), have enlightened the media and the public about the power of statistical data analysis. He'll be doing even more of that on ESPN, where he and his blog are moving later this year.

In fact, the media focus is international. I spoke in early January at the International Year kick-off event in Belgium. The regional newspaper sent a reporter and photographer, and Geert Molenberghs and I were interviewed at length. I can't resist showing you the result: a full page article. It's in Dutch, but you get the idea.

The interest in statistics has not been confined to the popular media. For example, the February 9, 2012 issue of Nature featured an article about the shortage of statisticians with the requisite skills to address genomic data challenges, stating that "statistical expertise has become more valuable than ever" (Hayden, 2012).

I could cite many more such accounts, just in the past year. If one relied solely on the proliferation of these, one would conclude that statisticians are the most soughtafter people on the planet and are critical to advances in science, business, and industry. Of course, we are. However, when it comes to reports covering Big Data and data science, we are conspicuously absent from many of them. 


\subsection{Invisibility of Statistics}

The term Big Data describes data sets that are so massive, complex, and intensive that traditional data management, processing, and analysis tools are infeasible. These data arise in business, scientific research, and government - from social networks, retail transactions, internet searches, and electronic medical records. And in genomics, meteorology, astronomy, military applications, and a host of other areas.

And what is data science? This emerging field is described as a blend of computer science, mathematics, data visualization, machine learning, distributed data management - and statistics - often in the context of Big Data. Its practitioners are portrayed as not only data analysts but as innovative problem solvers who are adept at handling and processing massive data. Who can create insightful visualizations. Who are so well-versed in the subject matter that they can not only uncover the story the data are telling but use it to advance domain knowledge. And who are superb communicators who are indispensable guides to business and scientific leaders.

Clearly, no one person can excel at all of these things. So, realistically, data science should be an interdisciplinary team endeavor. Involving statisticians. But while this much of this description sounds like a statistician, some of the skills mentioned are not possessed by many of us. Count me as one of them. Understanding of parallel computing, distributed data management, optimization on a massive scale, and new visualization tools. Proficiency in programming and scripting languages. The ability to work with unstructured text data, such as those arising from social networking interactions and electronic medical records.

But statistical skills are of course also critical to data science. A recent report from the National Academies of Science entitled "Frontiers in Massive Data Analysis" (National Research Council, 2013) states that "statistical rigor is necessary to justify 
the inferential leap from data to knowledge" in the massive data context. The report emphasizes the need for major new research efforts in statistical modeling, analysis, and design.

Nonetheless, we are missing from the public conversation. Accounts of data science appear almost daily in the popular and scientific press. But in many of these, our field is not being connected with this area. Entire articles on data science in which the words "statistics" or "statistician" never appear are not uncommon.

If statistics is mentioned, it may in passing. And often not as a contributing scientific discipline but rather as "tools" that a data scientist might use. Conventional statistical methods may be cited as not applicable to massive data structures. Or as too prescriptive. Computer scientists, physicists, and others are often highlighted as the innovative, "go-to" people for businesses and scientists with Big Data challenges.

A New York Times article in April (Miller, 2013) heralded the rise of data science, calling it "an emerging academic discipline" that is "so new (that) universities are scrambling to define it and develop curriculums." The article cites numerous examples of the formation of centers, institutes, and degree or certificate programs. Statistics is not identified as one of the key, relevant sciences. Instead, it is mentioned only as a skill and a course that might be required.

I have heard from many of you about presentations by campus, business, or agency leaders regarding new, data-oriented initiatives in which the words "statistics" or "statisticians" were never used. About university centers for Big Data and data science being conceived without consultation with the department of statistics. And about university administrators who have distinguished statistics from data science as a "traditional" field whose "tools" are not relevant to the new Big Data challenges.

I know that many of you are baffled by this disconnect. I know I am. Particularly 
given the positive press our field has otherwise enjoyed. As Larry Wasserman says in a post on his blog, Normal Deviate, "The very fact that people can talk about data science without even realizing there is a field already devoted to the analysis of data - a field called statistics - is alarming." (Wasserman, 2013).

Some members of our profession have expressed fear that departments of statistics could become obsolete if we do not act more aggressively to enter the data science arena. Others are skeptical, citing previous "hype" surrounding topics like data mining and neural networks, arguing that "this too shall pass."

This time, things may be different. Last March, the Obama Administration announced the "Big Data Research and Development Initiative," allocating more than $\$ 200$ million in federal funding for research, workforce, and technology initiatives. This past May, the White House Office of Science and Technology Policy (OSTP) held a Big Data workshop, attended by noted leaders in the data science movement. Another will be held in October. The National Institutes of Health (NIH) has created an agency-wide position, associate director for data science. NIH has announced a "Big Data to Knowledge" (BD2K) initiative, which "aims to facilitate broad use of biomedical Big Data," and just two weeks ago allocated $\$ 24$ million in annual funding for Big Data research "Centers of Excellence." The investments of the U.S. government alone suggest that Big Data and data science are here to stay.

Of course, complaining that data science is forging ahead without the benefit of our unique understanding of bias, confounding, false discovery, and uncertainty will not get us very far. We as a discipline must become more engaged. I will discuss ways we can do that shortly.

One final example illustrates an additional facet of the disconnect. Many of you may remember the February 11, 2011 issue of the journal Science. Science is published 
by the American Association for the Advancement of Science (AAAS). The AAAS is the world's largest general scientific society, with 120,000 members. And Science is one of the world's most prestigious general science publications. That issue was dominated by a special section devoted to "data." But the words "statistics" or "statistician" were hard to find in the numerous articles and columns.

This omission led to a meeting between several representatives of the ASA and Alan Leshner, the chief executive officer of the AAAS. Dr. Leshner was candid, telling his visitors that, "My impression is that many scientists view statistics not so much as a science but as a 'bag of tools.' " He encouraged our field to engage fellow scientists and make the case otherwise.

Many of us have domain science collaborators who have immense respect for our contributions. But many of us have also encountered this view of our discipline. This incident demonstrated how widespread it might very well be. I will discuss steps our association is taking to challenge it.

By now, most of us have heard about the 2011 report by the McKinsey Global Institute, a respected consulting firm (McKinsey, 2011). The report projects the need for up to 190,000 more people with serious data analytic expertise in the U.S. by 2018. I do not think you will argue with me if I assert that many, if not most or all, of those individuals should be statisticians or should have considerable background in statistics.

\section{RAISING AWARENESS}

I have just spent the last several minutes on some pretty heavy stuff. Do we really have a serious visibility problem? I think that the answer is, "Yes, and no."

On the one hand, we continue to play our critical roles as collaborators and re- 
searchers, and students are clamoring to major in our discipline and apply to our graduate programs. But on the other, we continue to be missing from the Big Data/data science conversation. And we do not have the recognition we deserve from some of our fellow scientists.

In addition, long-standing misunderstandings of the principles of statistics persist in the public sphere. My favorite example has to do with recent Congressional actions aimed eliminating the American Community Survey (ACS) conducted by the U.S. Census Bureau.

The ACS samples a small percentage of the U.S. population each year, and asks a detailed series of questions. Participation is mandatory, and the results are used to allocate over $\$ 400$ billion in funding. And private businesses use them for projection and planning. As reported in The New York Times last May (Rampell, 2012), one House member advocating elimination of the ACS remarked, "We're spending $\$ 70$ per person to fill this out. That's just not cost effective, especially since in the end this is not a scientific survey. It's a random survey." (Emphasis mine.)

Let me turn now to my second topic, what our association, the ASA, and the International Year of Statistics are doing to confront these challenges.

\subsection{The ASA}

The ASA is the second oldest continuously-operating professional society in the U.S., founded in Boston 1839. Only the American Philosophical Society, founded by Benjamin Franklin in 1743, is older. We will be celebrating our 175th anniversary next year. We have 19,000 members in more than 90 countries and are the world's largest community of statisticians. As Bob discussed in his presidential address last year, we aspire to be "The Big Tent for Statistics," which serves the needs of all who practice 
and use statistics.

Since 2008, we have had a formal strategic plan. It was updated in December 2012, and is organized around two main themes: "The ASA as "The Big Tent for Statistics" " and "Increasing the Visibility of the Profession." The plan is available on our website.

The second theme calls for stimulating awareness of the role of statistics and statisticians in science, government, and business and promoting the need for sound statistical practice to inform public and science policy. Objectives that speak directly to the issues I've raised.

In the past five years, the ASA has added two key staff positions whose responsibilities focus on these objectives. One resulted from an initiative launched by 2006 President Sallie Keller to enhance ASA's role in science policy, which became part of the strategic plan.

In 2008, Steve Pierson joined the ASA as our first Director of Science Policy. Steve has worked tirelessly to elevate awareness of statistics. I encourage you to visit the "Policy \& Advocacy" section of the ASA website to see the results of his efforts. I'll highlight just a few.

Steve was instrumental in the involvement of expert statisticians in the annual Climate Science Day on Capitol Hill, held annually since 2011, highlighting the key contributions of statistics. He has promoted ASA's activities in urging forensic science reform. Steve has worked with the Senate Office of Education and Training to bring talented statistician instructors to Capitol Hill to teach statistical principles to Congressional staff through our association's "Stats for Staffers" series. He has forged ties with the White House OSTP and has arranged opportunities for ASA leaders to participate in Big Data workshops. And to meet with OSTP leaders to emphasize 
the importance of statistics in data science.

Steve also writes columns and blogs to keep ASA members and the public informed. He is the force behind ASA Board statements and letters to government officials highlighting the role of statistics. In fact, as part of our efforts to alter the perception of statistics among AAAS members, Steve advocated for the opportunity for Tom Louis and me to write a Science editorial on statistics (Davidian and Louis, 2012), which appeared last April.

This last success inspired me to propose a broader initiative to raise the profile of statistics among scientists, focusing on doing this first within the AAAS. The ASA president-elect formulates several initiatives every year based on the themes in the strategic plan, and this is one of mine.

You may know that AAAS has 24 sections, including Section U on Statistics, founded by Jerzy Neyman. And that Section U celebrated its fiftieth anniversary last year. A workgroup of members of both AAAS and ASA, including Section U officers, has spearheaded a campaign to encourage statisticians to join AAAS and participate in AAAS activities - the more of us there are, the more of a voice we'll have. So far, Section U membership is up 14\%. And statistics students entering the challenging AAAS Student Poster Competition at the 2013 AAAS annual meeting won two of the four prestigious travel awards. At that meeting, Section U sponsored six, standing-room-only invited sessions, which competed against sessions from across the spectrum of science for inclusion on the program. And at least three Section U sessions have been accepted so far for the 2014 program.

You may recognize these buttons from this and the last JSM. If you interact with other scientists in your work, I encourage you to join AAAS and contribute to this ongoing outreach effort. 
Last year, with the International Year of Statistics looming and the 175th anniversary right behind, the ASA Board recognized that the ASA could no longer go without full-time public relations assistance. Jeff Myers joined us in 2012 as Public Relations Coordinator.

Jeff immediately got to work undertaking extensive outreach to the media. He has issued press releases on Statistics2013 and the contributions of statisticians in a host of areas. These have spawned inquiries, and Jeff has worked quickly to connect journalists to statistician experts. And to identify opportunities for ASA leaders to be heard in the media. Jeff has reached out to other organizations, including AAAS, and discussions of joint initiatives are ongoing.

An especially exciting development is the ASA Huffington Post blog. Seeing Jeff's many press releases, the Huffington Post contacted him about the possibility of a blog on statistics. Jeff recruited me to write the first two posts (Davidian, 2013). Since then, he has identified a diverse range of topics and enlisted notable members of our profession to contribute entries. The latest, on data science, is by Joel Greenhouse (Greenhouse, 2013).

Jeff is working with ASA executive director Ron Wasserstein to undertake an extensive public relations campaign for 2014 .

These are just some of the many ways Jeff is helping us to explain the power of statistics to the public.

\subsection{Statistics 2013}

Jeff has also played a major role in the International Year of Statistics. He coordinates much of the content on the Statistics2013 website, statistics2013.org. If you have not had the opportunity to explore the site, I encourage you to do so. It is an engaging, 
comprehensive introduction to the contributions of our field, featuring continually updated articles, blogs, teacher resources, and career information. The hope is that this wonderful resource will be maintained in perpetuity.

How did 2013 get to be the International Year of Statistics? Believe it or not, it started with... chemistry. I'm sure that you all know that 2011 was the International Year of Chemistry. My former department head, Sastry Pantula, who also happened to be 2010 ASA president, heard about this during a department head's meeting. If you know Sastry, you know that the wheels started turning before he left the room. Sastry immediately shared his idea with Ron. And the International Year of Statistics was born.

And quickly became a collaboration of five founding organizations: ASA, the Institute of Mathematical Statistics (IMS), the International Biometric Society (IBS), the International Statistical Institute (ISI) and the Bernoulli Society, and the Royal Statistical Society (RSS). A steering committee of nine representatives from these organizations worked tirelessly to create the website, spearhead events, and encourage worldwide participation. We owe them a huge debt of gratitude.

In November, a capstone event, the Future of the Statistical Sciences Workshop, will be held in London. The Workshop will chart a vision for the future of our discipline. Anyone will be able to view it online live and after it takes place. This event is just one more example of efforts to promote and advance our discipline.

Statistics2013 now has well over 2000 global participating organizations. That number continues to grow. And the International Year continues to bring recognition to our field. In fact, if you visit the SAS campus in Cary, North Carolina, you will see these banners lining the main campus drive. Every business leader and data science guru who visits SAS sees them, too. 
And Steve Pierson deserves a major round of applause from all of us. His persistence in engaging the staff of my senator, Kay Hagan, has paid off. As you saw on the cover of the July Amstat News, in May, Senator Hagan introduced U.S. Senate Resolution 150, "To designate the year 2013 as the 'International Year of Statistics'." Steve also was instrumental in encouraging Rep. Jerry McNerney of California, who holds a $\mathrm{PhD}$ in mathematics, to present a recognition of the International Year on the House floor in June.

\subsection{Big Data and Data Science}

Statistics2013 and the efforts of Steve and Jeff are doing much to enhance the visibility

of our field. But what about the challenges we face on the Big Data/data science front?

Our association has been doing several things.

Since 2008, the ASA has published the journal Statistical Analysis and Data Mining, edited by David Madigan of Columbia University. A major focus is on data analysis problems associated with massive and complex datasets. Its audience is meant to be interdisciplinary and working in data intensive fields. Articles discuss the use of statistical and machine learning. Data mining. Visualization. Computationally intensive methods. If it sounds like data science, it is.

In the June Amstat News, President-elect Nat Schenker, Bob, and I announced an ASA initiative whose goal is to prepare interested members of our profession to engage with the data science community and collaborate on Big Data problems (Schenker, Davidian, and Rodriguez, 2013).

There is, of course, nothing stopping us as individuals from doing this, and some of us are. But, collectively, many of us who are interested are not engaged because 
we lack the knowledge to do so. Just as we must educate data scientists who are not statisticians about the critical importance of statistical thinking, we must be prepared to understand the new ways of thinking and skills used in data science and to integrate these with our own expertise.

We have launched three projects focused on attaining that knowledge. First, we have formed a workgroup that will recommend ways we can enhance our curricula to equip our students with the skills and experience to be valued team members in data science applications. This will culminate in an event at JSM 2014 and a summary report. Second, the ASA will sponsor a series of meetings with leaders at the forefront of aspects of data science in which we statisticians are not substantially engaged. The goal is to develop networks that will help ASA to understand the key knowledge that statisticians need and to promote statistical thinking. Finally, at the 2014 Conference

on Statistical Practice and JSM 2014, ASA will offer short courses on the analysis of unstructured text data.

This is just a start. We hope that this initiative will encourage efforts by individuals and groups in our profession to engage further with data scientists and to bridge the disconnect.

\section{THE FUTURE - HOW WE ALL CAN PLAY A ROLE}

Let me now turn to my final topic - what we all can do to ensure that our discipline continues to play its fundamental role in science, business, and government and is an integral part of the data revolution.

I've told you about what the ASA is doing to enhance the visibility of statistics on many fronts. But "the ASA" is not some all-powerful entity that intervenes on all our behalf. The ASA is all of us, its members. As our association, ASA can provide 
resources and infrastructure to the volunteers and staff who spearhead and carry out its activities. But, ultimately, it is the initiative of each of us that inspires what the ASA does.

Our field is diverse, and we all are engaged in different aspects of statistical practice. I ask you to consider what you and your colleagues at your institution, company, agency, or organization can do within your sphere of practice to raise awareness of statistics and its importance to science, to data science, and to the public. And to get involved.

No matter the sector in which you work, continue to promote the value and sound practice of statistics to your collaborators and institutional, agency, and company leaders. Perhaps even more forcefully, exploiting the attention our field has received.

Embrace the spirit of the International Year locally to promote the power of statistics to the public. Leverage the positive attention and partner with the local school district or science museum to host a "Statistics Day." Host an outstanding speaker for a public lecture. Pitch stories about statistics to the local media. Offer to speak at elementary and secondary schools about statistics careers and what you do.

If you interact with other scientists in your work, join the AAAS, and contribute to our association's ongoing outreach efforts to fellow scientists.

Data science is here to stay. And, as Rachel Schutt, a statistician who is at the forefront of data science has told me, this is great news if it attracts more talented people to data analysis. And to statistics. Rachel taught a course on data science at Columbia last fall and is co-author of a forthcoming book based on that experience. She cites myriad open problems that require adaptation of classical statistical methods and design principles to massive data. And for frameworks for thinking about 
inference in this setting. Our involvement is critical, lest erroneous conclusions be made and wheels reinvented. Perhaps badly or not at all.

Not all of us are confronting massive data challenges. Many of us have enough challenges with the small and medium data we see in our work! But if you are, or if you are just interested in learning more, join our effort to engage with data scientists and promote the value of statistical thinking. I know many of you already are doing this.

If you are in academia like I am, initiate discussions within your department about curriculum enhancement to prepare our students for the option to work in data science endeavors. Reach out to colleagues in computer science, mathematics, and elsewhere and to businesses and research organizations with massive, complex data problems. Show them why we are essential partners. Insist on being part of campus data science efforts if you are not already. Focus on equipping our students for the data revolution through coursework and research experiences informed by these connections.

Conceive events and opportunities that bridge disciplinary boundaries and bring scientists with massive data problems and statistical scientists together. We academics should reach out to industry data scientists. Invite them to present case studies that enlighten our students and reveal needed research directions.

Attend a data science Meetup and speak to the role of statistics. They're in every major city.

I know all of you, your organizations, and ASA Chapters are a lot more creative than I am. 


\section{CLOSING - CALL TO ACTION}

Next year, 2014, is the 175th anniversary of the founding of our association. Nothing would make me more excited than to see my successor, Nat, stand at the podium delivering his own presidential address and noting how much progress we have made. Further enhancing understanding of statistical thinking among the public and policy makers. And among our fellow scientists. Engaging and partnering with the data science community. Having them join our "Big Tent for Statistics" because doing so adds value to their work. Highlighting the value our unique skills bring to all data-driven endeavors.

I encourage all of us to rise to this challenge. In this International Year of Statistics, I hope you will join our association in demonstrating the unique power of our discipline to make a difference in our world.

\section{REFERENCES}

Bialik, C. (2012), "Statistical Habits to Add, or Subtract, in 2013," The Wall Street Journal, December 28. Available at http://online.wsj.com/article/SB10001424127887324669104578206201895302728.html.

Bialik, C. (2013), "Data Crunchers Now the Cool Kids on Campus," The Wall Street Journal, March 1. Available at http://online.wsj.com/article/SB10001424127887323478304578332850293360468.html.

Davidian, M. (2013), “2013: The International Year of ...Statistics," and "New Treatments, Your Health, and Statistics," Huffington Post. Available at http://www.huffingtonpost.com/marie-davidian/. 
Davidian, M. and Louis, T.A. (2012), "Why Statistics?" Science, 336, 12. Available at http://www.sciencemag.org/content/336/6077/12.summary.

Greenhouse, J.B. (2013), "Statistical Thinking: The Bedrock of Data Science," Huffington Post, July 26. Available at http://www.huffingtonpost.com/americanstatistical-association/statistical-thinking-the-bedrock-of-data-science_b_3651121.html.

Hardy, Q. (2012), "What Are the Odds That Stats Would Be This Popular?" The New York Times Bits, January 26. Available at http://bits.blogs.nytimes.com/2012/01/26/what-are-the-odds-that-stats-would-getthis-popular/.

Hayden, E.C. (2012), "Biostatistics: Revealing analysis," Nature, 482, 263-265. Available at http://www.nature.com/naturejobs/science/articles/10.1038/nj7384$263 a$.

Lohr, S. (2009), "For Todays Graduate, Just One Word: Statistics," The New York Times, August 5. Available at http://www.nytimes.com/2009/08/06/technology/06stats.html?_r=0.

McKinsey Global Institute (2011), "Big Data: The Next Frontier for Innovation, Competition, and Productivity." Available at http://www.mckinsey.com/insights/business_technology/big_data_the_next_frontier_for_innovation.

Miller, C.C. (2013), "Data Science: The Numbers of Our Lives," The New York Times, April 11. Available at http://www.nytimes.com/2013/04/14/education/edlife/universities-offer-coursesin-a-hot-new-field-data-science.html?pagewanted=all. 
National Research Council (2013), Frontiers in Massive Data Analysis. The National Academies Press. Available at http://www.nap.edu/catalog.php?record_id=18374.

Rampell, C. (2012), "The Beginning of the End of the Census?," The New York Times, May 19. Available at http://www.nytimes.com/2012/05/20/sunday-review/the-debate-over-the-americancommunity-survey.html.

Rodriguez, R.N. (2012), "A Major Trend: The Rise of Undergraduate Programs in Statistics," Amstat News, August 1. Available at http://magazine.amstat.org/blog/2012/08/01/prescornerundergradstats/.

Schenker, N., Davidian, M., and Rodriguez, R. (2013), "The ASA and Big Data," Amstat News, June1. Available at http://magazine.amstat.org/blog/2013/06/01/theasa-and-big-data/.

Silver, N. (2012), The Signal and the Noise: Why So Many Predictions Fail but Some Don't. New York: The Penguin Press.

Teitell, B. (2012), "The Allure of the Statistics Field Grows," The Boston Globe, November 21. Available at http://www.bostonglobe.com/lifestyle/style/2012/11/21/youcome-long-way-statistician-wake-nate-silver-spot-predictions-statistics-field-enjoyspost-election-bump/OTIvwHdmKXGKnGZJNYHObJ/story.html.

Wasserman, L. (2013), "Data Science: The End of Statistics?" Available at http://normaldeviate.wordpress.com/2013/04/13/data-science-the-end-of-statistics/. 